\title{
Luteal Coasting and Individualization of Human Chorionic Gonadotropin Dose after Gonadotropin-Releasing Hormone Agonist Triggering for Final Oocyte Maturation-A Retrospective Proof-of-Concept Study
}

\author{
Barbara Lawrenz ${ }^{1,2 *}$, Suzan Samir ${ }^{1}$, Nicolas Garrido ${ }^{3}$, Laura Melado ${ }^{1}$, Nils Engelmann ${ }^{1}$ \\ and Human M. Fatemi ${ }^{1}$
}

'IVF Department, IVI Middle-East Fertility Clinic, Abu Dhabi, United Arab Emirates, ${ }^{2}$ Obstetrical Department, Women's
University Hospital Tuebingen, Tuebingen, Germany, ${ }^{3}$ Statistical Department, IVI Foundation, Valencia, Spain

OPEN ACCESS

Edited by:

John Lui Yovich,

Pivet Medical Center, Australia

Reviewed by:

Matheus Roque,

ORIGEN - Center for Reproductive

Medicine, Brazil

Birgit Alsbjerg,

Skive Hospital, Denmark

*Correspondence:

Barbara Lawrenz

barbara.lawrenz@ivivf.com

Specialty section:

This article was submitted to

Reproduction,

a section of the journal

Frontiers in Endocrinology

Received: 28 October 2017

Accepted: 24 January 2018

Published: 15 February 2018

Citation:

Lawrenz B, Samir S, Garrido N,

Melado L, Engelmann $N$ and Fatemi HM (2018) Luteal Coasting

and Individualization of Human

Chorionic Gonadotropin Dose after Gonadotropin-Releasing Hormone Agonist Triggering for Final Oocyte

Maturation-A Retrospective

Proof-of-Concept Study.

Front. Endocrinol. 9:33.

doi: 10.3389/fendo.2018.00033
Ovarian stimulation in a gonadotropin-releasing hormone $(\mathrm{GnRH})$ antagonist protocol with the use of $\mathrm{GnRH}$ agonist for final oocyte maturation is the state-of-the-art treatment in patients with an expected or known high response to avoid or at least reduce significantly the risk for development of ovarian hyperstimulation syndrome (OHSS). Due to a shortened LH surge after administration of GnRH agonist in most patients, the luteal phase will be characterized by luteolysis and luteal phase insufficiency. Maintaining a sufficient luteal phase is crucial for achievement of a pregnancy; however, the optimal approach is still under debate. Administration of human chorionic gonadotropin (hCG) within $72 \mathrm{~h}$ rescues the corpora lutea function; however, the so far often used 1,500 IU still bear the risk for development of OHSS. The recently introduced concept of "luteal coasting" individualizes the luteal phase support by monitoring the progesterone concentrations and administering a rescue dosage of hCG when progesterone concentrations drop significantly. This retrospective proof-of-concept study explored the correlation between hCG dosages ranging from 375 up to 1,500 IU and the progesterone levels in the early and mid-luteal phases as well as the likelihood of pregnancy, both early and ongoing. The chance of pregnancy is highest with progesterone level $\geq 13 \mathrm{ng} / \mathrm{ml}$ at $48 \mathrm{~h}$ postoocyte retrieval. Among the small sample size of 52 women studied, it appears that appropriate progesterone levels can be achieved with hCG dosages as low as $375 \mathrm{IU}$. This may well optimize the chance of pregnancy while reducing the risk of OHSS associated with higher doses of hCG supplementation in the luteal phase.

Keywords: luteal coasting, GnRH agonist trigger, ovarian hyperstimulation syndrome, individualization of human chorionic gonadotropin dosage, luteal phase support

\section{INTRODUCTION}

Over the past few decades, increasing knowledge of ovarian physiology and the possibility to evaluate accurately the ovarian reserve has led progressively to individualization and tailoring of ovarian stimulation for in vitro fertilization (IVF) - treatment.

Final oocyte maturation is the crucial step in ovarian stimulation cycles for IVF to retrieve mature oocytes for further processing in the IVF laboratory. In gonadotropin-releasing hormone 
(GnRH) antagonist cycles, human chorionic gonadotropin (hCG) and GnRH agonist can be administered for final oocyte maturation. Meanwhile, in patients with an expected or known high response, stimulation in a $\mathrm{GnRH}$ antagonist protocol with the use of GnRH agonist for final oocyte maturation is the stateof-the-art treatment to avoid or at least reduce significantly the risk for the development of ovarian hyperstimulation syndrome (OHSS) (1).

The GnRH agonist dislocates the GnRH antagonist in the pituitary from the GnRH receptors. This results in a surge of $\mathrm{LH}$ and $\mathrm{FSH}$, inducing final oocyte maturation and ovulation (2). However, induced LH/FSH peak is shorter compared to a natural LH surge. The duration of the LH/FSH surge is critical for normal luteal function, and due to a shortened LH surge, the granulosa cells fail to complete luteinization, resulting in a corpus luteum with impaired secretory function and a shortened lifespan. Therefore, the luteal phase will be characterized by luteolysis and luteal phase insufficiency (3). Previously, it was assumed that all patients will develop severe luteolysis within a matter of 5 days after GnRH agonist trigger (3); however, recently, it was clearly demonstrated that luteolysis after $\mathrm{GnRH}$ agonist trigger is patient specific (4). Unfortunately, there are so far no established predictive parameters to estimate the severity of the luteolysis.

Furthermore, after introducing GnRH agonist for final oocyte maturation, the first studies using this approach reported a very poor reproductive outcome (5). Noticeably, standard luteal phase support with the use of vaginal progesterone could not counterbalance the severe luteal phase insufficiency, whereas the use of intensive luteal phase support, defined as daily $50 \mathrm{mg}$ i.m. Progesterone and estradiol supplementation could lead to implantation, clinical, and ongoing pregnancy rates, which are comparable with the rates after hCG trigger (6).

Human chorionic gonadotropin attaches and activates the same receptor as $\mathrm{LH}$, and in the absence of a $\mathrm{LH}$ signal from the pituitary, consequently hCG can rescue the corpus luteum function and prevent complete luteolysis, while it is administered within $72 \mathrm{~h} \mathrm{(7)}$ in the appropriate dosage (8). Hence, several studies have shown that the administration of 1,500 IU hCG $35 \mathrm{~h}$ after $\mathrm{GnRH}$ agonist trigger result in comparable pregnancy rates in respect to hCG trigger. Nevertheless, still some patients will develop OHSS $(9,10)$.

A new approach in the treatment of OHSS high-risk-patients is the "luteal coasting" (11). This concept individualizes the luteal phase support after GnRH agonist administration for final oocyte maturation by monitoring the progesterone concentrations closely and administering a rescue dosage of hCG when progesterone concentrations drop significantly (12). However, heretofore, the hCG dosage and timing prerequisite to prevent luteolysis and sustain corpora lutea function and the progesterone levels required to achieve and maintain a pregnancy have not clearly been identified yet.

In this proof of concept study, we analyzed the correlation between progesterone levels $48 \mathrm{~h}$ after oocyte-pick-up (OPU) and hCG dosages administered as luteal phase support to search for the accurate amount of hCG for achieving a pregnancy and avoiding OHSS.

\section{MATERIALS AND METHODS}

\section{Patients}

Information from 52 patients being treated between September 2015 and May 2017 for primary/secondary infertility and indication for ovarian stimulation for IVF/ICSI in IVI Middle East Fertility Clinic, Abu Dhabi, United Arab Emirates, and who received $\mathrm{GnRH}$ agonist for final oocyte maturation due to the risk for development of OHSS, as the ultrasound findings showed the existence of $\geq 13$ follicles of a diameter $\geq 11 \mathrm{~mm}$, as described by Papanikolaou et al. (13) was gathered for this retrospective study.

\section{Stimulation Protocol}

Hormonal stimulation was performed in $\mathrm{GnRH}$ antagonist protocols with recombinant FSH (Puregon ${ }^{\circledR}, \mathrm{MSD}$; Gonal $\mathrm{F}^{\circledR}$, MerckSerono) or human menopausal gonadotropin (Menogon ${ }^{\circledR}$ or Menopur ${ }^{\circledR}$, Ferring). The starting dosage was chosen according to the results of the anti-Müllerian hormone and antral follicle count (14). Starting on day 5, patients received a daily dosage of $0.25 \mathrm{mg}$ GnRH antagonist (Orgalutran ${ }^{\circledR}$, MSD or Cetrotide ${ }^{\circledR}$, MERCK) to prevent premature ovulation.

During the stimulation course, stimulation dosage was adapted to the individual patient's response. GnRH agonist trigger for final oocyte maturation was used to avoid OHSS as the ultrasound showed $>13$ follicles with a size of $\geq 11 \mathrm{~mm}$ (13). Patients received $0.3 \mathrm{mg}$ of Triptorelin (Decapeptyl ${ }^{\circledR}$, Ferring) for final oocyte maturation, as soon as $\geq 3$ follicles were $\geq 17 \mathrm{~mm}$ in diameter. OPU was performed $36 \mathrm{~h}$ later under mild sedation, aspirating all follicles of a size of $\geq 11 \mathrm{~mm}$.

\section{Luteal Phase Support}

Patients started luteal phase support, using vaginal progesterone suppositories on the evening of the OPU day with $400 \mathrm{mg}$ of progesterone (Cyclogest ${ }^{\circledR}$, manufactured by Actavis, UK). From day $\mathrm{OPU}+1$, the dosage was increased to $3 \times 400 \mathrm{mg}$.

Besides the luteal phase support through vaginal progesterone application, patients received individual dosages of hCG between 375 and 1,500 IU hCG $48 \mathrm{~h}$ after OPU. The administered hCG dosage did not follow a previously defined criteria; however, it was decided on the progesterone level $48 \mathrm{~h}$ after OPU and the clinical findings of the patient regarding abdominal swelling and lower abdominal pain. This approach was chosen for the high-responder patient as the fertilization law of the United Arab Emirates does not allow embryo freezing. The fertilization law of the United Arab Emirates (15) says in Article 11: “The Centre shall comply with the following with regard to the excess ova: ... 2. In the case of surplus fertilized ova in whatever manner, these ova shall be left without medical attention until they perish naturally."

\section{Endocrine Assessment}

Serum endocrine assessment of progesterone (P4) $48 \mathrm{~h}$ after OPU procedure/84 h after final oocyte maturation was conducted to assess the pattern of individual luteolysis. The measurements of the progesterone level after OPU procedure were run as a clinical routine to evaluate the need of additional hCG administration for the luteal phase support. 
Hormone levels (P4) were measured with the Cobas ${ }^{\circledR} 6000$ analyzer system, Roche. The upper measurable limit of progesterone levels with this system is $60 \mathrm{ng} / \mathrm{ml}$; therefore, levels above this limit will be also expressed as $60 \mathrm{ng} / \mathrm{ml}$.

For luteal phase support, additional to the vaginal progesterone application, hCG was administered after the result of progesterone measurement was available. The dosage was 375 , $750,1,000$, or 1,500 IU hCG and was chosen depending on the progesterone level and the clinical condition of the patient in respect to abdominal swelling or lower abdominal pain, following the clinics' established standard criteria and protocols and routine clinical practice.

Twelve days after embryo transfer (ET), a serum test for hCG was performed. The pregnancy test was considered to be positive when the hCG level was > 15 IU/l. An "on going" pregnancy was defined once positive heartbeat was visible in the ultrasound at 12 weeks. The patients with a positive hCG test, however without visible ultrasonographic pregnancy sac, were counted as "pregnancy loss." Patients with a negative pregnancy test were informed to stop the administration of vaginal progesterone.

The study was approved by the Ethic Committee of IVI Middle East Fertility Clinic, Abu Dhabi, United Arab Emirates (Research Ethics Committee IVI-ME_REC13_2017). Due to the fact that the herein analyzed measurements of progesterone levels were run as a clinical routine during IVF treatment, the ethic committee waived the need for obtaining oral or written approval from each patient.

\section{Data Analysis}

Exploratory data analysis allowed the evaluation of data quality and detecting/correcting anomalies and was followed by a descriptive analysis and statistical summary of the data collected in the study. Categorical data are shown as proportions and $95 \%$ confidence intervals, while continuous variables are summarized using the mean, ranges, SD, and 95\% confidence intervals.

Regarding the statistical analysis that was applied to fulfill each objective, to determine the association between quantitative values of the P4 $48 \mathrm{~h}$ after the administration of GnRH agonist and the rate of pregnancy/on going pregnancy we initially checked the normal distribution by means of Kolmogorov-Smirnoff tests, and then Student's $t$-test or Mann-Whitney's test, depending on the normal distribution or not, of the main variable were applied.

To determine the association between the levels of progesterone $48 \mathrm{~h}$ after administration of GnRH agonist, the amount of hCG given $48 \mathrm{~h}$ after final oocyte maturation, and the rate of pregnancy/ongoing pregnancy, analysis was performed in the two subgroups: those patients with hCG $\leq 750 \mathrm{IU}$ and the other one with hCG > 750 IU.

Data were analyzed with the Social Package for Social Sciences (SPSS) 23.0 software (Chicago, IL, USA), and statistical significance was established at $p<0.05$.

\section{RESULTS}

The mean age of all 52 included patients was 30.75 years, the mean body mass index (BMI) of the patients was 26.33. 12 days after the ET, 35 patients (67.30\%) had a positive pregnancy test and 17 patients $(32.70 \%)$ had a negative result.

The mean ages of the patients with a positive pregnancy test and a negative pregnancy test were 30.40 and 31.47 years, respectively. The mean BMIs of the pregnant/the non-pregnant patients were 25.95 and 27.08 , respectively.

In the whole group, the mean number of retrieved oocytes was 18.31 with a range from 9 to 31 oocytes. The mean number of oocytes was 18.54 oocytes for the patients with a positive pregnancy test and 17.82 for patients with a negative pregnancy test.

On the day of final oocyte maturation, the mean progesterone level for all patients was $0.73 \mathrm{ng} / \mathrm{ml}$. For the patients with a positive pregnancy test and a negative pregnancy test, the mean progesterone levels were 0.70 and $0.78 \mathrm{ng} / \mathrm{ml}$, respectively.

In all patients, the mean progesterone level $48 \mathrm{~h}$ after OPU was $29.89 \mathrm{ng} / \mathrm{ml}$. Patients with a positive pregnancy test had the mean progesterone level of $28.97 \mathrm{ng} / \mathrm{ml}$, and patients with a negative pregnancy test had the mean progesterone level of $31.79 \mathrm{ng} / \mathrm{ml}$. There was no significant correlation between $\mathrm{P} 4$ level $48 \mathrm{~h}$ after OPU and the achievement of a pregnancy $(p=0.200)$.

The differences for the parameters age, BMI, number of retrieved oocytes, mean progesterone levels on the day of final oocyte maturation, and $48 \mathrm{~h}$ after OPU were statistically not significant.

The mean number of transferred embryos was 1.67 in the total group. A mean number of 1.86 embryos had been transferred in the pregnant patients and 1.29 embryos in the group of nonpregnant patients. The difference was statistically significant between the groups $(p<0.001)$.

Embryo transfer was performed on day 2 (1 case), day 4 (11 cases), day 5 (32 cases), and day 6 (8 cases). The results, including the ranges and the $95 \%$ confidence interval, are shown in Table 1.

The further analysis evaluated the group of patients who achieved a pregnancy to investigate whether there is a correlation between progesterone levels $48 \mathrm{~h}$ after OPU and an ongoing pregnancy/pregnancy loss. Of 35 patients with a positive pregnancy test, 30 patients (85\%) had an ongoing pregnancy and 5 patients (15\%) lost the pregnancy before a viable pregnancy was seen in the ultrasound. Patients with an ongoing pregnancy had a mean P4 level of $29.98 \mathrm{ng} / \mathrm{ml}$, and patients with a pregnancy loss had a mean P4 level of $22.90 \mathrm{ng} / \mathrm{ml}$. The differences for the parameters age, BMI, number of retrieved oocytes, and mean progesterone levels on the day of final oocyte maturation and $48 \mathrm{~h}$ after OPU were statistically not significant. There was also no statistically significant difference in the number of transferred embryos in patients who had an ongoing pregnancy and those with a pregnancy loss (1.87 vs 1.80). There was no significant correlation between the P4 level $48 \mathrm{~h}$ after OPU and the outcome (on going pregnancy yes/no) of the pregnancy $(p=0.081)$. Table 2 summarizes the data of the subgroup analysis.

Human chorionic gonadotropin was given to the patient after the progesterone result was available to avoid luteal phase insufficiency. No patient developed early or late OHSS as a result of the hCG dosage administered for luteal phase support. 1 patient did not have any hCG at all during the luteal phase (progesterone level $40.0 \mathrm{ng} / \mathrm{ml} 48 \mathrm{~h}$ after OPU). hCG was administered in dosages of $375,750,1,000$, or 1,500 IU to $12,33,4$, and 2 patients, respectively. 
TABLE 1 | Summary of demographics and stimulation characteristics of the patients: all, pregnant, and non-pregnant patients.

\begin{tabular}{|c|c|c|c|c|}
\hline Parameter & Mean & Range & $\begin{array}{c}95 \% \\
\text { confidence } \\
\text { interval }\end{array}$ & Significance \\
\hline \multicolumn{5}{|l|}{ Age (years) } \\
\hline All patients & 30.75 & $22-45$ & 29.28-32.22 & n.s. \\
\hline Pregnant patients & 30.4 & $22-43$ & 28.68-32.12 & \\
\hline Non-pregnant patients & 31.47 & $23-45$ & $28.44-34.50$ & \\
\hline \multicolumn{5}{|l|}{ BMI (kg/m²) } \\
\hline All patients & 26.33 & $18.15-36.6$ & $25.21-27.44$ & n.s. \\
\hline Pregnant patients & 25.95 & $19.72-33.25$ & $24.65-27.25$ & \\
\hline Non-pregnant patients & 27.08 & $18.15-36.16$ & $24.78-29.37$ & \\
\hline \multicolumn{5}{|c|}{ Number of retrieved oocytes } \\
\hline All patients & 18.31 & $9-31$ & $16.85-19.76$ & n.s. \\
\hline Pregnant patients & 18.54 & $9-31$ & $16.78-20.39$ & \\
\hline Non-pregnant patients & 17.82 & $9-29$ & $14.96-20.69$ & \\
\hline \multicolumn{5}{|c|}{ Mean progesterone level day of final oocyte maturation $(\mathrm{ng} / \mathrm{ml})$} \\
\hline All patients & 0.73 & $0.24-1.38$ & $0.66-0.80$ & n.s. \\
\hline Pregnant patients & 0.70 & $0.3-1.18$ & $0.61-0.88$ & \\
\hline Non-pregnant patients & 0.78 & $0.6-1.2$ & $0.69-0.88$ & \\
\hline \multicolumn{5}{|c|}{ Mean progesterone level $48 \mathrm{~h}$ after OPU (ng/ml) } \\
\hline All patients & 29.89 & $13-56$ & $27.06-32.73$ & n.s. \\
\hline Pregnant patients & 28.97 & $13-56$ & $25.31-32.63$ & \\
\hline Non-pregnant patients & 31.79 & $18-45$ & $27.09-36.48$ & \\
\hline \multicolumn{5}{|c|}{ Number of embryos transferred } \\
\hline All patients & 1.67 & $1-2$ & $1.54-1.8$ & $p<0.001$ \\
\hline Pregnant patients & 1.86 & $1-2$ & $1.74-1.98$ & \\
\hline Non-pregnant patients & 1.29 & $1-2$ & $1.05-1.54$ & \\
\hline \multicolumn{5}{|c|}{ Mean day of embryo transfer } \\
\hline All patients & 4.81 & $2-6$ & $4.62-4.99$ & n.s. \\
\hline Pregnant patients & 4.89 & $4-6$ & $4.70-5.07$ & \\
\hline Non-pregnant patients & 4.65 & $2-6$ & $4.20-5.09$ & \\
\hline
\end{tabular}

Data expressed as means with their corresponding 95\% Cl.

BMI, body mass index; n.s., not significant; OPU, oocyte-pick-up.
For those groups, the mean progesterone levels and the ranges were calculated. In the groups of hCG administration of 375,750 , 1,000 , or $1,500 \mathrm{IU}$, mean progesterone levels were $37.03 \mathrm{ng} / \mathrm{ml}$ (range, $22-43 \mathrm{ng} / \mathrm{ml}$ ), $28.26 \mathrm{ng} / \mathrm{ml}$ (range, $15.8-51.25 \mathrm{ng} / \mathrm{ml}$ ), $20.9 \mathrm{ng} / \mathrm{ml}$ (range, $14-21.8 \mathrm{ng} / \mathrm{ml}$ ), and $26.75 \mathrm{ng} / \mathrm{ml}$, respectively.

To evaluate the influence of the dosage of administered hCG and the achievement of a pregnancy, correlation between hCG dosages above and below 750 IU hCG and the pregnancy outcome was performed.

Of the six patients receiving 1,000 or 1,500 IU hCG, four patients $(66.66 \%)$ did not achieve a pregnancy and two patients (33.33\%) had a positive pregnancy test. The mean progesterone level of the patients in this group was $22.87 \mathrm{ng} / \mathrm{ml}$. The patients without positive pregnancy test had a mean P4 level of $27.55 \mathrm{ng} / \mathrm{ml}$, and patients with a pregnancy had a mean progesterone level of $13.50 \mathrm{ng} / \mathrm{ml}$. There was no significant correlation between the application of a hCG $>750$ and the achievement of a pregnancy $(p=0.133)$.

46 patients received a dosage of 750 IU hCG or less. In this group, the mean $\mathrm{P} 4$ level was $30.81 \mathrm{ng} / \mathrm{ml}$. Of this group, 13 patients $(28.26 \%)$ had no pregnancy and 33 patients $(71.73 \%)$ achieved a pregnancy. The mean P4 levels were 33.09 and $29.91 \mathrm{ng} / \mathrm{ml}$, respectively. There was no significant correlation between the application of a hCG $\leq 750$ and the achievement of a pregnancy $(p=0.2)$. Table 3 shows ranges, the $95 \% \mathrm{CI}$ and the correlation between the applied hCG dosage and the achievement of a pregnancy.

To evaluate a possible correlation in the pregnant patients between the amount of administered hCG (above 750 IU hCG or $\leq 750$ IU hCG), a pregnancy, and the progesterone levels $48 \mathrm{~h}$ after OPU, those parameters were correlated with each other. Of the group of patients receiving 375 or 750 IU hCG, 33 patients had a positive pregnancy test. 29 of them (87.87\%) had an ongoing pregnancy and four patients did not. In these groups, mean P4 levels were $25.12 \mathrm{ng} / \mathrm{ml}(\mathrm{SD}, \pm 14.657)$ and 30.57

TABLE 2 | Summary of subgroup analysis between patients with an ongoing pregnancy and a pregnancy loss.

\begin{tabular}{|c|c|c|c|c|}
\hline & Ongoing pregnancy & Pregnancy loss & $\begin{array}{l}\text { Significance (between the groups "ongoing } \\
\text { pregnancy" and "pregnancy loss") }\end{array}$ & $\begin{array}{c}\text { Non-pregnant } \\
\text { patients }\end{array}$ \\
\hline Number of patients & $30(85 \%)$ & $5(15 \%)$ & n.a. & 17 (32.7\%) \\
\hline Mean age (years) & 30.80 & 28.00 & n.s. & 31.47 \\
\hline $95 \% \mathrm{Cl}$ & $28.85-32.75$ & $24.38-31.62$ & & $28.44-34.50$ \\
\hline $\mathrm{BMl}$ & 26.27 & 24.08 & n.s. & 27.08 \\
\hline $95 \% \mathrm{Cl}$ & $24.78-27.75$ & 22.06-26.11 & & $24.78-29.37$ \\
\hline Number of retrieved oocytes & 18.73 & 17.40 & n.s. & 17.82 \\
\hline $95 \% \mathrm{Cl}$ & $16.75-20.72$ & $12.46-22.34$ & & $14.96-20.69$ \\
\hline $\begin{array}{l}\text { Mean progesterone level day of final oocyte } \\
\text { maturation }(\mathrm{ng} / \mathrm{ml})\end{array}$ & 0.72 & 0.58 & n.s. & 0.78 \\
\hline $95 \% \mathrm{Cl}$ & $0.62-0.83$ & $0.29-0.88$ & & $0.69-0.88$ \\
\hline Mean progesterone level $48 \mathrm{~h}$ after OPU (ng/ml) & 29.98 & 22.90 & n.s. & 31.79 \\
\hline $95 \% \mathrm{Cl}$ & $26.24-33.72$ & $5.97-39.82$ & & 27.09-36.48 \\
\hline Mean number of embryos transferred & 1.87 & 1.80 & n.s. & 1.29 \\
\hline $95 \% \mathrm{Cl}$ & $1.74-2.00$ & $1.24-1.36$ & & $1.05-1.54$ \\
\hline Mean day of transfer & 5 & 5 & n.s. & 4.88 \\
\hline
\end{tabular}

Data expressed as means with their corresponding 95\% Cl.

BMI, body mass index; n.a., not applicable; n.s., not significant; OPU, oocyte-pick-up. 
TABLE 3 | Correlation between hCG dosage >750 IU or $\leq 750 \mathrm{IU}$ and achievement of pregnancy.

\begin{tabular}{|c|c|c|c|c|}
\hline Amount of hCG for LPS & \multicolumn{2}{|c|}{$\leq 750$ IU hCG } & \multicolumn{2}{|c|}{$>750$ IU hCG } \\
\hline Number of patients & \multicolumn{2}{|c|}{46} & \multicolumn{2}{|c|}{6} \\
\hline Mean progesterone level and range $48 \mathrm{~h}$ after OPU (ng/ml) & \multicolumn{2}{|c|}{$30.81(16-56)$} & \multicolumn{2}{|c|}{$22.87(13-40)$} \\
\hline $95 \% \mathrm{Cl}$ & \multicolumn{2}{|c|}{$27.87-33.74$} & \multicolumn{2}{|c|}{$11.75-33.99$} \\
\hline Pregnancy & Yes & No & Yes & No \\
\hline Number of patients & 33 & 13 & 2 & 4 \\
\hline Mean progesterone level 48 h after OPU (ng/ml) & $29.91(16-56)$ & $33.09(18-45)$ & $13.50(13-14)$ & $27.55(18-40)$ \\
\hline $95 \% \mathrm{Cl}$ & $26.27-33.54$ & $27.74-38.45$ & $7.15-19.85$ & $11.70-43.40$ \\
\hline Correlation between pregnancy yes/no and hCG dosage & \multicolumn{2}{|c|}{$\mathrm{No}(p=0.2)$} & \multicolumn{2}{|c|}{ No $(p=0.131)$} \\
\hline
\end{tabular}

hCG, human chorionic gonadotropin; OPU, oocyte-pick-up.

(SD, \pm 9.655$)$, respectively. In patients with hCG administration of 375 or 750 IU, there was no significant correlation between $\mathrm{P} 4$ levels and an ongoing pregnancy $(p=0.184)$. Of the two patients, receiving previously 1,000 or $1,500 \mathrm{IU}$ hCG, one patient had an ongoing pregnancy and the other patient had a biochemical pregnancy, with progesterone levels of 13 and $14 \mathrm{ng} / \mathrm{ml}$, respectively. Table 4 shows the correlation between the applied hCG dosage, progesterone level 48 hours after OPU, and the ongoing pregnancy (yes/no).

\section{DISCUSSION}

To optimize the approach of "luteal coasting" and minimize the risk for development of OHSS after GnRH agonist trigger due to an inadequate high hCG dosage, knowledge of the interaction between progesterone levels in the early luteal phase and the "optimal" hCG dosage is extremely important.

After administration of GnRH agonist for final oocyte maturation, pulsatile $\mathrm{LH}$ secretion continues; however, the mean $\mathrm{LH}$ concentrations and LH pulse amplitudes are lower than those described for a natural cycle in the early luteal phase. Therefore, the process of luteolysis starts very early in the luteal phase, as progesterone and estradiol levels drop 2 days after ovulation (16). Maintenance of adequate levels of progesterone is crucial for implantation. The first studies, using a standard luteal phase support with vaginal progesterone after GnRH agonist trigger found a significantly lower implantation rate and clinical pregnancy rate in addition to a significantly higher rate of early pregnancy loss (5).

The optimal approach to maintain a sufficient luteal phase is still under debate notwithstanding the fact that the use of $\mathrm{GnRH}$ agonist for final oocyte maturation is nowadays the state-of-theart treatment for expected or known high responder to avoid OHSS $(9,17,18)$. This is especially important as the "freeze-all" and "cycle segmentation" policy (19) is not applicable for all patients due to various reasons.

Corpora lutea function can be easily maintained through the application of hCG by timely administration. The first studies administered an arbitrarily chosen bolus of 1,500 IU hCG $35 \mathrm{~h}$ after GnRH agonist trigger (9). Due to the occurrence of OHSS cases despite the reduced dosages $(9,10)$, other authors evaluated the administration of even lower hCG dosages some on a daily basis. However, even with these lower dosages, OHSS could not
TABLE 4 | Correlation between hCG dosage >750 IU and $\leq 750 \mathrm{IU}$, progesterone level $48 \mathrm{~h}$ after OPU, and an ongoing pregnancy (yes/no).

\begin{tabular}{|c|c|c|c|c|}
\hline $\begin{array}{l}\text { Amount of hCG } \\
\text { for LPS }\end{array}$ & \multicolumn{2}{|c|}{$\leq 750$ IU hCG } & \multicolumn{2}{|c|}{$\begin{array}{c}>750 \text { IU } \\
\text { hCG }\end{array}$} \\
\hline $\begin{array}{l}\text { Number of patients } \\
\text { with pregnancy }\end{array}$ & \multicolumn{2}{|c|}{33} & \multicolumn{2}{|r|}{2} \\
\hline $\begin{array}{l}\text { Ongoing } \\
\text { pregnancy }\end{array}$ & Yes & No & Yes & No \\
\hline Number of patients & 29 & 4 & 1 & 1 \\
\hline $\begin{array}{l}\text { Mean progesterone } \\
\text { level } 48 \text { h after OPU } \\
\text { (ng/ml) }\end{array}$ & $25.12(1.80-48.44)$ & 30.57 (26.90-34.24) & 13 & 14 \\
\hline $\begin{array}{l}\text { Correlation between } \\
\text { ongoing pregnancy } \\
\text { and hCG dosage }\end{array}$ & \multicolumn{2}{|c|}{ No $(p=0.184)$} & \multicolumn{2}{|c|}{ n.s. } \\
\hline
\end{tabular}

Data expressed as means with their corresponding 95\% Cl.

hCG, human chorionic gonadotropin; n.a., not applicable; n.s., not significant;

OPU, oocyte-pick-up.

be avoided completely $(20,21)$. Therefore, further individualization of hCG administration in the context of the luteal coasting approach is required to reduce furthermore the OHSS risk after $\mathrm{GnRH}$ agonist trigger (12). The aim of this retrospective analysis is to evaluate the correlation between the applied hCG dosages, depending on the serum progesterone levels $48 \mathrm{~h}$ after OPU and the pregnancy rate as well as the ongoing pregnancy rate. The approach of administration of individualized hCG dosages, based on the individual luteolysis and the clinical findings of the patient was chosen, as the fertilization law of the United Arab Emirates does not allow embryo freezing.

This proof-of-concept-study supports the idea that early OHSS development seems to be avoidable by individualization of luteal phase support through the administration of reduced hCG dosages without impacting the ART outcome. However, it is very important that the hCG is administered timely enough to rescue the corpora lutea with the subsequent progesterone production. Those findings have to be supported by a bigger sample size.

The current analysis showed that achievement of a pregnancy as well as the outcome of the pregnancy [ongoing pregnancy (yes/no) until 12 weeks of gestation] are not correlated with the P4 levels we have mentioned, i.e., with $13 \mathrm{ng} / \mathrm{ml}$ being the lowest level in our study group $48 \mathrm{~h}$ after OPU ( $p=0.200$ and $p=0.0081$ ). According to these results, it can be assumed that the amount of "progesterone drop-down" $48 \mathrm{~h}$ after OPU even toward a level of 
$13 \mathrm{ng} / \mathrm{ml}$ does not have any impact on the chance of achieving and/or maintaining a pregnancy, as long as a hCG bolus will rescue the corpora lutea function and therefore maintain a sufficient luteal phase support. However, the data regarding a lower limit of progesterone levels, which are still sufficient to achieve and maintain a pregnancy after the use of GnRH antagonist, are limited.

Moreover, no significant correlation between the application of a hCG bolus $>750$ or $\leq 750$ and the achievement of a pregnancy ( $p=0.133$ and $p=0.2$ respectively) was found. In addition, the amount of administered hCG does not seem to have an influence regarding the maintenance of the pregnancy, as there was no significant correlation between the P4 levels, the hCG dosage of $\leq 750$ or $>750 \mathrm{IU}$, and the outcome of the pregnancy [ongoing pregnancy (yes/no) until 12 weeks of gestation; $p=0.184$ and $p=0.064$ respectively].

These data indicate that the hCG dosage of 1,500 IU, previously chosen as a "rescue-bolus" (9) can be reduced on individual bases, without having a negative impact on the chance of pregnancy or the chance for an ongoing pregnancy.

Csapo et al. (22) demonstrated that early pregnancy can only be maintained under sufficient corpora lutea function or progesterone replacement in case of a loss of the corpus luteum. Luteal phase deficiency in a natural cycle is defined when the midluteal progesterone levels are measured below $10 \mathrm{ng} / \mathrm{ml}(31.8 \mathrm{nmol} / \mathrm{l})$ or a sum of three random serum $\mathrm{P}$ measurements $<30 \mathrm{ng} / \mathrm{ml}$ (95.4 nmol/l) (23). Hence, it is not clear whether these levels are also sufficient in an ART cycle due to the previous ovarian stimulation, which results in supraphysiological hormonal levels. Recently, it was demonstrated that in ART cycles, pregnancies can be achieved and maintained even with early luteal phase progesterone levels of $13 \mathrm{ng} / \mathrm{ml}$ when a hCG bolus was administered for luteal phase support (24).

All patients in this retrospective analysis administered $3 \times 400 \mathrm{mg}$ vaginal progesterone for luteal phase support, which will also contribute to the measured serum progesterone levels.

The contribution of the vaginal progesterone toward the serum progesterone levels cannot be determined. However, it can be assumed that the contribution was low as it was previously demonstrated that serum progesterone levels measured after vaginal progesterone administration are even lower than in natural cycle (25).

Our current data support the idea that a hCG dosage below $1,500 \mathrm{IU}$ is sufficient to maintain adequate progesterone levels in early and mid-luteal phase and to allow implantation. From day

\section{REFERENCES}

1. Dosouto C, Haahr T, Humaidan P. Gonadotropin-releasing hormone agonist (GnRHa) trigger - state of the art. Reprod Biol (2017) 17(1):1-8. doi:10.1016/j. repbio.2017.01.004

2. Gonen Y, Balakier H, Powell W, Casper RF. Use of gonadotropin-releasing hormone agonist to trigger follicular maturation for in vitro fertilization. J Clin Endocrinol Metab (1990) 71:918-22. doi:10.1210/jcem-71-4-918

3. Fatemi HM, Polyzos NP, van Vaerenbergh I, Bourgain C, Blockeel C, Alsbjerg B, et al. Early luteal phase endocrine profile is affected by the mode of triggering final oocyte maturation and the luteal phase support used in recombinant follicle-stimulating hormone-gonadotropin-releasing hormone antagonist
7 of fertilization, the embryo will start producing hCG by itself (26), and from that point of time, endogenous produced hCG will cover the LH deficit caused by the supraphysiologic steroid levels (27) and avoid regression of the corpora lutea.

The weakness of the current proof-of-concept study is the limited number of patients evaluated; therefore, statistical analysis of the outcomes was not feasible as the different embryo numbers transferred cannot be adjusted for, e.g., by logistical regression analysis. The hCG dosage did not follow previously defined criteria and was decided on the progesterone level $48 \mathrm{~h}$ after OPU and the clinical findings of the patient regarding abdominal swelling and lower abdominal pain. To define a treatment algorithm, future studies should evaluate the ART outcome in a prospective randomized controlled study with previously defined hCG dosage depending on the progesterone level.

\section{CONCLUSION}

Luteal phase support after final oocyte maturation with $\mathrm{GnRH}$ agonist in a GnRH antagonist protocol is still under discussion. Most patients are receiving similar luteal phase supports and the administration of a hCG rescue bolus of 1,500 IU stills bears the risk of OHSS development. The current proof-of-concept study demonstrates that the hCG dosage can be individualized, and therefore, it seems that OHSS after GnRH agonist administration for final oocyte maturation can be avoided by dosage reduction of the hCG rescue bolus without impacting the chance of achieving and/or maintaining a pregnancy. Despite the small sample size, this proof-of-concept study is important to be seen as a possible approach in high-responder patients, in whom freezing of embryos might not be applicable due to various reasons.

\section{ETHICS STATEMENT}

The retrospective analysis was approved by the Ethic Committee of IVI Middle East Fertility Clinic, Abu Dhabi, United Arab Emirates (Research Ethics Committee IVI-ME_REC13_2017).

\section{AUTHOR CONTRIBUTIONS}

BL: concepted the analysis and wrote the manuscript. SS: data collection. NG: statistical analysis of the data. LM: involved in patient's treatment and review of manuscript. NE: review of manuscript. HF: supervision of the study concept and review of manuscript.

in vitro fertilization cycles. Fertil Steril (2013) 100:742-7. doi:10.1016/j. fertnstert.2013.05.028

4. Lawrenz B, Garrido N, Samir S, Ruiz F, Melado L, Fatemi HM. Individual luteolysis pattern after GnRH-agonist trigger for final oocyte maturation. PLoS One (2017) 12(5):e0176600. doi:10.1371/journal.pone.0176600

5. Humaidan P, Bredkjaer HE, Bungum L, Bungum M, Grøndahl ML, Westergaard L, et al. GnRH agonist (buserelin) or hCG for ovulation induction in GnRH antagonist IVF/ICSI cycles: a prospective randomized study. Hum Reprod (2005) 20:1213-20. doi:10.1093/humrep/deh765

6. Engmann L, DiLuigi A, Schmidt D, Nulsen J, Maier D, Benadiva C. The use of gonadotropin-releasing hormone $(\mathrm{GnRH})$ agonist to induce oocyte maturation after cotreatment with GnRH antagonist in high-risk patients undergoing 
in vitro fertilization prevents the risk of ovarian hyperstimulation syndrome: a prospective randomized controlled study. Fertil Steril (2008) 89(1):84-91. doi:10.1016/j.fertnstert.2007.02.002

7. Hutchison JS, Zeleznik AJ. The corpus luteum of the primate menstrual cycle is capable of recovering from a transient withdrawal of pituitary gonadotropin support. Endocrinology (1985) 117:1043-9. doi:10.1210/endo-117-3-1043

8. Dubourdieu S, Charbonnel B, Massai MR, Marraoui J, Spitz I, Bouchard P. Suppression of corpus luteum function by the gonadotropin-releasing hormone antagonist Nal-Glu: effect of the dose and timing of human chorionic gonadotropin administration. Fertil Steril (1991) 56:440-512. doi:10.1016/ S0015-0282(16)54537-3

9. Humaidan P. Luteal phase rescue in high-risk OHSS patients by GnRHa triggering in combination with low-dose HCG: a pilot study. Reprod Biomed Online (2009) 18:630-4. doi:10.1016/S1472-6483(10)60006-5

10. Seyhan A, Ata B, Polat M, Son WY, Yarali H, Dahan MH. Severe early ovarian hyperstimulation syndrome following $\mathrm{GnRH}$ agonist trigger with the addition of 1500 IU hCG. Hum Reprod (2013) 28:2522-8. doi:10.1093/humrep/det124

11. Lawrenz B, Humaidan P, Kol S, Fatemi HM. GnRHa trigger and luteal coasting - a new approach for the OHSS high-risk patient? Reprod Biomed Online (2018) 36(1):75-7. doi:10.1016/j.rbmo.2017.09.014

12. Kol S, Breyzman T, Segal L, Humaidan P. 'Luteal coasting' after GnRH agonist trigger - individualized, HCG-based, progesterone-free luteal support in 'high responders': a case series. Reprod Biomed Online (2015) 31(6):747-51. doi:10.1016/j.rbmo.2015.09.001

13. Papanikolaou EG, Pozzobon C, Kolibianakis EM, Camus M, Tournaye H, Fatemi HM, et al. Incidence and prediction of ovarian hyperstimulation syndrome in women undergoing gonadotropin-releasing hormone antagonist in vitro fertilization cycles. Fertil Steril (2006) 85:112-20. doi:10.1016/j. fertnstert.2005.07.1292

14. La Marca A, Sunkara SK. Individualization of controlled ovarian stimulation in IVF using ovarian reserve markers: from theory to practice. Hum Reprod Update (2014) 20:124-40. doi:10.1093/humupd/dmt037

15. Health Authority Abu Dhabi. Book 7, Fertilization Law. (2014). Available from: http://aafc.ae/media/1221/uae-law-english-version.pdf

16. Tannus S, Burke Y, McCartney CR, Kol S. GnRH-agonist triggering for final oocyte maturation in GnRH-antagonist IVF cycles induces decreased LH pulse rate and amplitude in early luteal phase: a possible luteolysis mechanism. Gynecol Endocrinol (2017) 33(9):741-5. doi:10.1080/09513590.2017.1318275

17. Christopoulos G, Vlismas A, Carby A, Lavery S, Trew G. GnRH agonist trigger with intensive luteal phase support vs. human chorionic gonadotropin trigger in high responders: an observational study reporting pregnancy outcomes and incidence of ovarian hyperstimulation syndrome. Hum Fertil (Camb) (2016) 19(3):199-206. doi:10.1080/14647273.2016.1217432

18. Andersen CY, Fischer R, Giorgione V, Kelsey TW. Micro-dose hCG as luteal phase support without exogenous progesterone administration: mathematical modelling of the hCG concentration in circulation and initial clinical experience. J Assist Reprod Genet (2016) 33(10):1311-8. doi:10.1007/ s10815-016-0764-7

19. Devroey P, Polyzos NP, Blockeel C. An OHSS-Free Clinic by segmentation of IVF treatment. Hum Reprod (2011) 26(10):2593-7. doi:10.1093/humrep/ der251

20. Castillo JC, Dolz M, Bienvenido E, Abad L, Casañ EM, Bonilla-Musoles F. Cycles triggered with GnRH agonist: exploring low-dose HCG for luteal support. Reprod Biomed Online (2010) 20:175-81. doi:10.1016/j.rbmo.2009.11.018

21. Andersen CY, Elbaek HO, Alsbjerg B, Laursen RJ, Povlsen BB, Thomsen L, et al. Daily low-dose hCG stimulation during the luteal phase combined with GnRHa triggered IVF cycles without exogenous progesterone: a proof of concept trial. Hum Reprod (2015) 30:2387-95. doi:10.1093/humrep/dev184

22. Csapo AI, Pulkkinen MO, Kaihola HL. The relationship between the timing of luteectomy and the incidence of complete abortions. Am J Obstet Gynecol (1974) 118(7):985-9. doi:10.1016/0002-9378(74)90671-1

23. Jordan J, Craig K, Clifton DK, Soules MR. Luteal phase defect: the sensitivity and specificity of diagnostic methods in common clinical use. Fertil Steril (1994) 62(1):54-62. doi:10.1016/S0015-0282(16)56815-0

24. Lawrenz B, Samir S, Melado L, Ruiz F, Fatemi HM. Luteal phase serum progesterone levels after $\mathrm{GnRH}$-agonist trigger - how low is still high enough for an ongoing pregnancy? Gynecol Endocrinol (2017) 16:1-4. doi:10.1080/09513590. 2017.1391204

25. Tavaniotou A, Smitz J, Bourgain C, Devroey P. Comparison between different routes of progesterone administration as luteal phase support in infertility treatments. Hum Reprod Update (2000) 6:139-48. doi:10.1093/ humupd/6.2.139

26. Fishel SB, Edwards RG, Evans CJ. Human chorionic gonadotropin secreted by preimplantation embryos cultured in vitro. Science (1984) 11:816-8. doi:10.1126/science. 6546453

27. Fatemi HM, Popovic-Todorovic B, Papanikolaou E, Donoso P, Devroey P. An update of luteal phase support in stimulated IVF cycles. Hum Reprod Update (2007) 13(6):581-90. doi:10.1093/humupd/dmm021

Conflict of Interest Statement: The authors state that there is no conflict of interest. Also the research was conducted in the absence of any commercial or financial relationships.

Copyright $\odot 2018$ Lawrenz, Samir, Garrido, Melado, Engelmann and Fatemi. This is an open-access article distributed under the terms of the Creative Commons Attribution License (CC BY). The use, distribution or reproduction in other forums is permitted, provided the original author(s) and the copyright owner are credited and that the original publication in this journal is cited, in accordance with accepted academic practice. No use, distribution or reproduction is permitted which does not comply with these terms. 